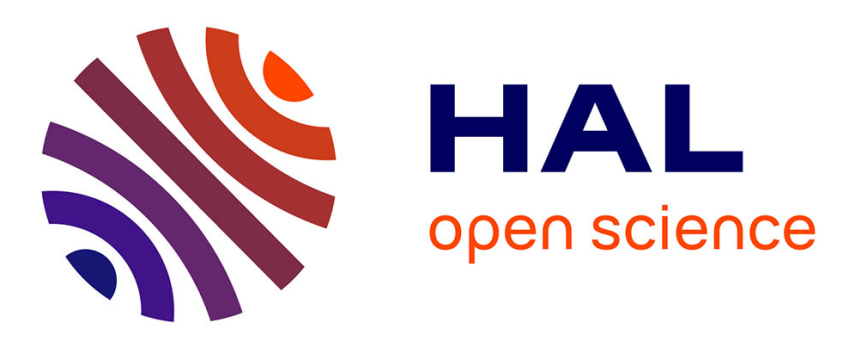

\title{
Experimental study of a liquid film flowing over a perforation
}

Manasa Iyer, Joel Casalinho, Jacopo Seiwert, Mikael Wattiau, Hervé Duval

\section{To cite this version:}

Manasa Iyer, Joel Casalinho, Jacopo Seiwert, Mikael Wattiau, Hervé Duval. Experimental study of a liquid film flowing over a perforation. AIChE Journal, 2021, 67 (11), 10.1002/aic.17363 . hal03436550

\section{HAL Id: hal-03436550 https://hal.science/hal-03436550}

Submitted on 19 Nov 2021

HAL is a multi-disciplinary open access archive for the deposit and dissemination of scientific research documents, whether they are published or not. The documents may come from teaching and research institutions in France or abroad, or from public or private research centers.
L'archive ouverte pluridisciplinaire HAL, est destinée au dépôt et à la diffusion de documents scientifiques de niveau recherche, publiés ou non, émanant des établissements d'enseignement et de recherche français ou étrangers, des laboratoires publics ou privés. 


\section{Experimental study of a liquid film flowing over a perforation}

Manasa IYER ${ }^{1,2}$, Joel CASALINHO ${ }^{1}$, Jacopo SEIWERT ${ }^{2}$, Mikael WATTIAU², Hervé DUVAL ${ }^{1}$

1 Université Paris-Saclay, CentraleSupélec, Laboratoire de Génie des Procédés et Matériaux, 91190, Gif-sur-Yvette, France.

2 Campus Innovation Paris, Air Liquide Research \& Development, 1, chemin de la Porte des Loges, 78350 Les Loges-en-Josas, France.

Corresponding author: Hervé Duval (herve.duval@centralesupelec.fr)

Abstract: Perforations are one of the recognized geometrical features that contribute to liquid redistribution in corrugated sheet packings. Our experimental study focuses on a simplified but relevant configuration: a thin liquid film flowing on either side of a vertical plate with a circular perforation.

We focus on the curtain mode when the liquid fills the perforation. Confocal chromatic imaging reveals a capillary ridge upstream of the perforation, an inertial ridge downstream and a varicose capillary wave standing on the liquid curtain. We show that the wavelength is selected such that the velocity of the wave both satisfies Taylor's dispersion relation and matches the curtain local speed.

We examine the effect of perforation size, supply conditions and liquid properties on the curtain transition. Lastly, we propose a simple model based on a momentum balance that describes the effect of these parameters on the Reynolds number at which curtain forms.

Topical Heading: Transport Phenomena and Fluid Mechanics

Key Words: Structured packing, perforated sheet, liquid curtain, film thickness, varicose waves 


\section{Introduction}

Corrugated sheet packings have been introduced in the 1970s and widely applied since then in distillation and absorption columns ${ }^{1}$. Such packings are composed of thin vertical crimped sheets stacked parallel to each other. In cryogenic air separation, the sheets are typically made of aluminum. These structured packings combine high packing void fraction and high interfacial area. This results in lower pressure drop, higher efficiency and higher capacity as compared to trays. The way the liquid distributes, spreads over the packing sheets and eventually forms a film impacts the liquid-vapor interfacial area, the mass-transfer and the subsequent separation efficiency of the column ${ }^{2}$. In a corrugated sheet packing, three kinds of geometrical features contribute to liquid distribution: the corrugations ${ }^{3}$, the perforations ${ }^{4}$ and optionally the microtexture whose characteristic length scale is typically one to several orders of magnitude lower than the corrugations. Perforations let the liquid flow from one side of corrugated sheet to the other side. As a consequence, they promote liquid exchange between the two sides of a same sheet and reduce the accumulation of liquid in the corrugation trough to avoid channel flow ${ }^{4}$. A common value of hole diameter is $4 \mathrm{~mm}$ and the standard opening rate of the sheets is $12.6 \%$. Most of the corrugated sheet packing have perforations.

Whereas the effect of the corrugations on liquid distribution ${ }^{3}$, liquid film thickness ${ }^{5}{ }^{6}$, liquid film stability ${ }^{7-10}$, waves formation ${ }^{11}$ and mass-transfer ${ }^{12,13}$ has been extensively investigated, there is very little published work on perforations and their impact on liquid film flow.

Pavlenko et al. ${ }^{4}$ studied experimentally the effect of perforations on liquid distribution for a single vertical aluminum perforated-corrugated sheet (although the main subject of this paper is the effect of microtexture). Only one side (front) of the sheet was supplied with liquid (the rear side is irrigated by the holes). Two perforation diameters were investigated: $4 \mathrm{~mm}$ and 10 $\mathrm{mm}$. The liquid was liquid nitrogen. Pavlenko et l $^{4}{ }^{4}$ distinguished different regimes depending 
on the film Reynolds number (Re defined in the next section). For $100 \leq \operatorname{Re} \leq 225$, the entire surface of the sheet front side is wetted by liquid nitrogen, with no dry patch. 3D waves of high amplitude travel on the liquid free surface except in regions beneath the holes. These calm waveless zones become narrower and shorter as the flow rate increases. Droplets and jets detach periodically from the top edge of the $10 \mathrm{~mm}$ holes. For $50 \leq \mathrm{Re} \leq 100$, longer and wider waveless zones extend below the $4 \mathrm{~mm}$ holes. Non-wetted areas appear beneath the 10 $\mathrm{mm}$ holes. For $10 \leq \operatorname{Re} \leq 50$, dry zones extend beneath the $4 \mathrm{~mm}$ and $10 \mathrm{~mm}$ holes. These patches become wider and longer as the liquid flow rate decreases. Detachment of droplets and jets from hole top edge ceases. Travelling waves become 2D. For the whole range $(10 \leq \operatorname{Re} \leq$ 225), a significant flow of liquid though the holes (from the front side to the rear side) is observed.

Xie et al. ${ }^{14}$ experimentally studied the film flow over a vertical aluminum plane plate with a single large perforation. Only one face of the plate was supplied with liquid. Six liquids were used with Kapitza number (Ka defined in the next section) from 52 up to 2930. The film Reynolds number was varied in the range $0-200$. Xie et al. ${ }^{14}$ investigated different perforation geometries but most of the results concern centimetric rectangular perforations. These so-called "open windows" are actually novel elements for gas-liquid contact that show interesting mass transfer performances ${ }^{15,16}$. Xie et al. ${ }^{14}$ found a diversity of flow patterns. For Re $<14$ (interval given for water), the liquid "passes around" the window forming a rim upstream, no liquid in the window and a dry patch downstream. For $14 \leq \operatorname{Re}<125$, droplets form periodically from the top edge of the window and spill on the bottom edge. As Re is increased, the liquid drops more and more frequently and turn to steady columns, which bridge the top edge to the bottom edge of the window. For $\operatorname{Re}>125$, the columns coalesce to form a pendant sheet. For even greater values of Re, a liquid curtain completely fills the window. This curtain exhibits a pattern of capillary waves. When liquid "passes through" the window (in the form of droplets, 
columns, pendant sheet or curtain), a part of the liquid flows from the front side to the back side of the plate. Xie et al. ${ }^{14}$ also propose an empirical correlation for the film Reynolds number at liquid curtain transition. They note a hysteresis: the film Reynolds number for liquid curtain rupture is several times lower. In a second paper, Xie et al. ${ }^{17}$ further investigated the curtain regime using computational fluid dynamics (CFD). This regime is referred to as twinliquid films by these authors because of the coexistence of a supported film on the solid plate and a suspended liquid film in the open window. Simulations were performed with two side liquid inlets. The suspended liquid film exhibits stationary varicose capillary waves. The characteristics of the wave pattern agree well with the experimental observations (carried out with two face supply). Furthermore, the numerical simulations evidence strong vorticity generation both inside the wavy suspended film and on its free surface. These phenomena contribute to the mass transfer intensification observed for the plate with open window (as compared to the unperforated plate) ${ }^{16}$.

The sequence of flow patterns observed for a large rectangular perforation is close to the sequence typically seen in horizontal-tube falling-film heat exchangers. Bundles of horizontal tubes are widely used in refrigeration, desalination and food industries for example. Hu \& Jacobi $^{18}$ distinguished three idealized modes, i.e. droplet, jet and sheet modes (classified by increasing Reynolds number) and, in between, mixed modes, i.e. combination of two idealized modes. For each mode transition, $\mathrm{Hu} \& \mathrm{Jacobi}^{18}$ propose an empirical correlation for the transitional Reynolds number as a function of the Galileo number $\left(\mathrm{Ga}=\mathrm{Ka}^{3}\right)$, for increasing and decreasing flow rate (since the transitions exhibit hysteresis). The correlation of Xie et al. ${ }^{14}$ for rectangular perforation involves the same dimensionless numbers.

The film flow over a perforation (through hole) has also some similarities with the flow over topographies such as step-in, step-out, trench or blind (non through) holes. There is an abundant literature on this subject ${ }^{19}$. It appears that a topography step is preceded by a standing capillary 
wave: a capillary ridge before a step-in, a free surface depression before a step-out ${ }^{20,21}$. As the film Reynolds number increases, a so-called inertial ridge appears after a step-out ${ }^{22}$. The same features were observed by Xie et al. ${ }^{14,17}$ at the entrance and at the exit of a rectangular open window.

To better understand the effect of perforations on liquid redistribution and potential mass transfer enhancement in corrugated sheet packings, we presently consider a thin liquid film flowing on a vertical plane plate with a circular perforation. We address the different flow patterns and focus on the curtain mode: we will carefully characterize the curtain transition and the curtain mode for a broad range of perforation diameters (including standard values encountered in industrial packings), several plate thickness, different flow conditions (one side and two side supply with independent and controlled liquid flow rates) and various liquids. In particular, the local deformation of the film around and within the perforation will be assessed using confocal chromatic imaging (CCI).

In the first part of the paper, we briefly address the physics of the problem and identify the main dimensionless numbers that control the curtain transition. In the second part, we describe our original experimental setup and the measurement methods used to characterize the thin liquid film. In the third part, the different patterns of a liquid film flowing over a perforation are presented as a function of hole diameter and flow rate conditions. In the fourth part, we study in-depth the effect of hole parameters, plate supply conditions and liquid physical properties on the curtain transition threshold. In the fifth part, dedicated to the discussion, we propose a simple momentum balance to account for the curtain transition and give a physical picture of the curtain behavior.

\section{Problem description}

Liquid flows within industrial corrugated-perforated packing are very difficult to observe directly since the stacked sheets are opaque and the geometry is very intricate. In order to 
experimentally investigate the hydrodynamics of the thin liquid film flowing in and around the perforations of a sheet, we simplify the structure of a packing and consider a single perforation on a vertical flat plate (see Figures 1 and 2). $x$ denotes the streamwise direction, $y$ the spanwise direction and $z$ the direction in the depth of the liquid film. In this simple geometry, upstream conditions can be carefully monitored and the effect of perforation on the film hydrodynamics is isolated from other topography effects such as corrugations. The perforation is characterized by its diameter $(d)$ and the plate by its thickness $(t)$. The front side and the back side of the plate are indexed by $i=1$ and 2 , respectively.

We consider a Newtonian liquid with constant density $(\rho)$, dynamic viscosity $(\mu)$ and surface tension $(\sigma)$. We suppose that the equilibrium contact angle $\left(\theta_{E}\right)$ of the liquid on the plate is significantly lower than $\pi / 2$. Then, wetting is favorable. Each side $(i)$ of the plate is supplied with liquid at a volume flow rate per unit width $\left(Q_{i}\right)$ with $Q_{2} \leq Q_{1}$. Two limiting cases are considered, i.e. $Q_{2}=0$ corresponding to one face supply and $Q_{1}=Q_{2}$ corresponding to two face supply with equal flow rates. When a face is supplied with a non-zero volume flow rate, we suppose that this volume flow rate is high enough to completely wet the solid face. We assume that the film flows are steady and laminar and that the perforation is placed in the fully developed region. We are aware that a liquid film falling on a vertical flat plate is unconditionally unstable. However, we suppose that the amplitude of the waves travelling on the free surface remains much lower than the film thickness. Under these assumptions, in the established regime and in absence of perforation, the liquid film has a uniform thickness and the velocity profile is semi-parabolic as found by Nusselt ${ }^{23}$. The film thickness on the $i$ side is then given by $\delta_{N u}\left(Q_{i}\right)=\left(3 v Q_{i} / g\right)^{1 / 3}$ for a vertical plate, where $v$ denotes the liquid kinematic viscosity. This thickness is called the Nusselt thickness of the falling film. Two other characteristic lengths can be defined, i.e. the capillary length $l_{c}=(\sigma / \rho g)^{1 / 2}$ by balancing the 
surface tension forces with gravity and the visco-gravitational length $l_{v}=v^{2 / 3} / g^{1 / 3}$ by balancing the viscous forces with gravity ${ }^{23}$.

Let us assume that the perforation diameter is large, i.e. greater than the plate thickness and the capillary length of the liquid.

When the volume flow rate is low, the film flows around the perforation without filling it. On the contrary, when the volume flow rate is high, a liquid curtain closes the perforation (see the photographs displayed later in the paper). The transition between these two modes is expected to occur when the inertia of the film balances the surface tension forces, i.e. when the Weber number of the film is of the order of $1^{24}$. For two face supply with equal flow rates, this reads $\rho\left(Q_{c r}\right)^{2} /\left(\delta_{N u}\left(Q_{c r}\right) \sigma\right) \approx 1$ where $Q_{c r}$ is the flow rate per unit width on one side of the plate at the curtain transition. In other words, curtain transition occurs when the liquid mean velocity $Q_{c r} / \delta_{N u}\left(Q_{c r}\right)$ is of the order of the Culick $^{25}$ retraction velocity of the curtain $\left(\sigma /\left(\rho \delta_{N u}\left(Q_{c r}\right)\right)\right)^{1 / 2}$. This relation can be recast in the following scaling law

$$
\mathrm{Re}_{c r} \approx \mathrm{Ka}^{3 / 5}
$$

$\operatorname{Re}_{c r}$ is the Reynolds number of the film flow at the curtain transition. For the sake of brevity, we will later refer to it as the curtain Reynolds number. Re compares the inertial forces with the viscous forces acting on the film flowing on the front side $(i=1)$ of the plate. It is given by $\operatorname{Re}=Q_{1} / v=\frac{1}{3}\left(\delta_{N u}\left(Q_{1}\right) / l_{v}\right)^{3}$. Ka is the Kapitza number. It compares the effects of surface tension to the viscous and gravitational effects, i.e. Ka $=\left(l_{c} / l_{v}\right)^{2}=\sigma /\left(\rho g^{1 / 3} v^{4 / 3}\right)$. Ka only depends on the physical properties of the liquid.

In the general case, the problem is governed by 8 parameters, i.e. $\rho, v, \sigma, g, Q_{1}, Q_{2}, d$ and $t$, that can be expressed in terms of 3 independent dimensions. According to the VaschyBuckingham theorem, the problem can be fully described by 5 dimensionless parameters. From the above analysis, we choose the next set of independent dimensionless parameters: Re, 
$Q_{2} / Q_{1}, \mathrm{Ka}, d / l_{c}$ and $t / d$. Then, the Reynolds number of the film flow at the curtain transition reads $\operatorname{Re}_{c r}=f\left(\mathrm{Ka}, Q_{2} / Q_{1}, d / l_{c}, t / d\right)$.

In the following, the dimensionless parameters are varied in order to investigate the flow modes of the film falling on the front side of the perforated plate and determine the Reynolds number at the curtain transition.

\section{Experimental setup}

\section{Materials}

The test plates are cut from aluminum sheets. The plate length in the streamwise direction is $L=200 \mathrm{~mm}$ and the plate width in the spanwise direction is $B=150 \mathrm{~mm}$ (see Figure 1 ). Three different plate thickness are studied: $t=0.5,1$ and $1.5 \mathrm{~mm}$. The perforation is made by drilling for $t=1$ and $1.5 \mathrm{~mm}$ and by laser cutting for $t=0.5 \mathrm{~mm}$. Special care is taken when machining in order to maintain the flatness of the sheet and ensure that the edge of the perforation is sharp and perpendicular to the plate face. The center of the perforation is located on the midline of the plate, at $60 \mathrm{~mm}$ from the top edge. Eight perforation diameters are studied: $d=2,4,6,8,10,12,14$ and $16 \mathrm{~mm}$. The test plates are slightly polished with abrasive (grit size P1200) to get a matt rendering thus reducing the impact of parasitic reflections on optical based measurements. The resulting roughness parameter ( $\mathrm{Ra}$, arithmetical average of the roughness profile) of the plate is measured by confocal chromatic imaging (3D Measuring Station with CHR 150-N sensor, STIL). Measurements are performed in two orthogonal directions, streamwise $(x)$ and spanwise $(y)$, in the proximity of the perforation and far from the perforation. Ra ranges from 0.2 to $0.5 \mu \mathrm{m}$.

Four liquids are used in the experiments: pure propan-2-ol, $55 \mathrm{wt} \%$ glycerin aqueous solution, $25 \mathrm{wt} \%$ glycerin aqueous solution and pure water. Pure propan-2-ol has been purchased from VWR Chemicals (GPR Rectapur ${ }^{\circledR}>99.0 \%$ ). Pure water is delivered by a Millipore Milli-Q 
purification system. Glycerin solutions are prepared from pure glycerin (Rotipuran $®>99.5 \%$, p.a., anhydrous, Carl Roth) and pure water: after weighing the components, the mixture is stirred until a homogeneous and perfectly clear solution is obtained. The final density of the solution is adjusted to the tabulated value ${ }^{28}$ by a small addition of glycerin. Since liquid properties may alter over time (due to contamination, development of microorganisms and/or biochemical degradation), glycerin solutions are used within $36 \mathrm{~h}$ after making. Milli-Q water is used the day of the delivery. Propan-2-ol is used in the week. The physical properties of the working liquids are reported in Table 1 . We choose these liquids to cover a wide range of Kapitza numbers, i.e. more than one order of magnitude. Furthermore, the wetting of the aluminum sheets is favorable for the four liquids (equilibrium contact angle $\theta_{E}<90^{\circ}$ ).

\section{Experimental setup}

The setup itself (Figure 1) comprises three parts: the frame that holds the perforated plate, the liquid circuit and the instrumentation dedicated to liquid film observation and measurement. The perforated plate is inserted in a rigid frame to ensure its flatness. The frame is held vertically. It is decoupled from the other parts of the device and mounted on an anti-vibration table to damp the parasitic vibrations that may affect the fluid film flowing on the plate. Each face of the plate is supplied with liquid by a distributor. The liquid circulates thanks to a magnet gear pump (MDG-M15T3B, Iwaki). The volumetric flow rate delivered by each distributor is independently set by a needle control valve and monitored by an oval gear volumetric flow meter (MX06, MacNaught). The liquid flowing from the bottom of the plate comes into a collector and then returns to the feeding tank.

The centerpieces of the liquid circuit are the two distributors. They have been carefully designed (over approximately ten iterations) in order to uniformly distribute the liquid in the spanwise direction of the plate. They are made in the shape of a diffuser and mounted with an inclination of $10^{\circ}$ with respect to the horizontal. Because of this slope, the liquid ascends in the 
distributors. Entry of air is then avoided and the distributors remain filled with liquid even at low liquid flow rates. Liquid inside the distributors is guided through a set of square blocks which spreads the flow in the spanwise direction and also breaks down the large eddies. Finally, the flow comes out laminar through 30 horizontally and equally spaced circular nozzles of 2 $\mathrm{mm}$ in diameter.

The liquid flow pattern is observed and recorded using a CMOS high-speed camera (v310, Phantom) mounted with a macro lens (AF Zoom-Micro Nikkor 70-180mm f/4.5-5.6D ED, Nikon). Images are captured with a resolution of $1200 \times 800 \mathrm{px}^{2}$ and with an acquisition frequency of $1.8 \mathrm{kHz}$. For shadowgraph imaging of the suspended film, the back side of the plate is illuminated with a LED panel. When looking at the supported film free surface, the front side is lit by a cold light illuminator (KL 2500 LCD, Schott).

The instantaneous local thickness of the liquid film is measured using confocal chromatic imaging (sensor CL4, STIL). This technique has already been implemented to measure the thickness of films flowing on a flat surface ${ }^{30} 31$. Since the sensor is capable of detecting multiple interfaces such as solid-liquid, liquid-liquid and liquid-gas, the plate-supported film and the suspended film that bridges the perforation can be both characterized. Film thickness is measured with a precision better than $0.5 \mu \mathrm{m}$ at acquisition frequency of $5 \mathrm{kHz}$.

\section{Experimental protocol}

First, the test plate is cleaned with a surfactant solution (3 vol\%, Mucasol, Merz), thoroughly rinsed with distilled water and dried with compressed air. Then, it is inserted and fixed in the vertical frame. The outlet of the distributors is positioned on the front side and on the back side of the plate, about two millimeters below the top edge of the plate. The distance (in $z$ direction) and parallelism between the nozzles and the plate is carefully adjusted in order to obtain later on a liquid film with a uniform thickness in the spanwise $(y)$ direction. Since the outlet is located $58 \mathrm{~mm}$ upstream of the perforation, the film flow is fully developed at the location of 
the perforation. We also rigorously checked that the amplitude of the waves travelling on the liquid film upstream of the perforation remains small compared to the film thickness (see annex A1 in Supplementary Material).

Both faces of the plate are fed with the highest flow rate, i.e. $65 \mathrm{~L} \cdot \mathrm{h}^{-1}$, such that the liquid is forced to wet the whole usable width of the plate, i.e. $w=90 \mathrm{~mm}$. Then, the liquid flowrate can be reduced down to $5 \mathrm{~L} \cdot \mathrm{h}^{-1}$ and the region upstream of the perforation remains totally covered by the liquid film.

For the supply condition $Q_{1} / Q_{2} \neq 1\left(Q_{2}<Q_{1}\right)$, the flowrate that supplies the back side of the plate $\left(Q_{2}\right)$ is first fixed at its target value. Then, the flowrate of the plate front side $\left(Q_{1}\right)$ is progressively increased, in increments of $1 \mathrm{~L}^{-\mathrm{h}^{-1}}$, in order to explore the different regimes of the film flow around and over the perforation. We determine the flow rate per unit width at the curtain transition $\left(Q_{c r}\right)$ as follows: $Q_{c r}$ is associated with the smallest flow value for which there is a stable curtain that entirely closes the perforation. For the supply condition $Q_{1} / Q_{2}=$ 1, the flowrates are identically initialized and increased simultaneously with the same increments. The transitions of the film flow are observed by shadowgraph imaging. Optionally, the topography of the liquid film near the perforation is investigated point-by-point by CCI. For each set of parameter values, experiments were performed at least in triplicate. Details about calibration and reliability tests are given in annex A1 (see Supplementary Material).

\section{Flow modes over a perforation}

\section{Far below the curtain transition}

We presently report experiments carried out with propan-2-ol at low values of the Reynolds number. We find that the liquid film flow is deflected by the perforation and does not fill it (see the photograph of Figure 3). We observe an arch-shaped stationary capillary ridge: its apex is located upstream of the perforation close to the stagnation point and the legs of the arch extend downstream. The ridge flattens and widens far from the perforation. It divides the downstream 
region of the flow in an outer region and an inner region, the film thickness in the outer (resp. inner) region being generally larger (resp. lower) than the Nusselt thickness of the film far upstream. In the outer region, the liquid film thickness decays in an oscillatory manner and tends towards the Nusselt thickness far from the ridge (see Figure 3).

In the inner region, (just downstream of the perforation), the liquid film is very thin or even missing when $Q_{2} / Q_{1}=0$. When $Q_{2} / Q_{1}=1$ (we remind that $Q_{1} \geq 5{\mathrm{~L} . \mathrm{h}^{-1}}^{-1}$ ), the liquid also flows along the inner surface of the perforation from both sides of the plate and a thin liquid film forms downstream of the perforation. When $Q_{2} / Q_{1}=0$, the contact line is pinned at the inner surface of the perforation, there is a dry patch downstream of the perforation and there is no fluid transfer from the front side to the back side of the plate. This dry region expands downstream as the perforation diameter increases. The presence of a dry zone beneath the holes at low flow rates was also observed by Pavlenko et $a l .{ }^{4}$ on corrugated-perforated sheets and by Xie et al. ${ }^{14}$. behind centimetric rectangular perforations.

The graph of Figure 3 focuses on the free surface profile in the $y=0$ plane near the perforation. CCI film thickness measurements are reported for $Q_{2} / Q_{1}=1$ and $Q_{2} / Q_{1}=0$. Data are missing close to the top and bottom edges of the perforation: CCI fails to capture the film thickness because the local slope of the free surface is too steep with respect to the vertical plate. Figure 3 shows that the height of the capillary ridge for one face supply is significantly greater than for two face supply with equal volumetric flow rate. Indeed, in case of a liquid film flowing over a step-in or trench, it is well known that the ridge height increases with the depth of that topography ${ }^{21,32}$. In two (resp. one) face supply, the depth of the topography seen by the liquid film is the plate half-thickness (resp. entire thickness). Thus, the capillary overpressure and the ridge height required to push the liquid inside the perforation are greater for one face supply. 
Lastly, we also observe 2D horizontal waves traveling in the streamwise direction downstream of the perforation (see Figure 3). The wavelength is estimated at about $10 \mathrm{~mm}$, i.e. one order of magnitude greater than the film thickness. These are Kapitza waves ${ }^{33}$.

\section{Prior to the curtain transition}

As the liquid flow rate increases, the train of upstream capillary ridges shifts toward the perforation. Ultimately, the leading ridge may go down into the perforation and form a rim within the perforation. This phenomenon occurs at $\mathrm{Re}=23$ for propan-2-ol and one face supply. It coincides with the onset of liquid transfer from the front side to the back side of the plate. On the backside, the liquid climbs over the top edge of the perforation and makes an arch-shaped capillary ridge whose legs extend in the form of two parallel rivulets. The rivulets widen and flatten downstream.

Depending on perforation diameter and $Q_{2} / Q_{1}$, different rim dynamics and transitions to the curtain mode are observed. We report thereafter a diversity of flow patterns (see Figure 4). We emphasize that this diversity cannot be seen sequentially for a same perforation when increasing the film Reynolds number (as for a large rectangular perforation for example ${ }^{14}$ ). The transition from the "pass around" mode to the curtain mode occurs generally through one intermediate mode that depends on the perforation diameter

Hereafter are reported the transitions observed for propan-2-ol. Unless otherwise specified, the same modes are observed for water and glycerin mixtures.

\section{Oscillating rim}

For small perforation diameters $(d=2-8 \mathrm{~mm})$, irrespective of plate thickness and liquid properties, an oscillating liquid rim is observed in the perforation as shown in Figure 4a-b. The hole (in the liquid film) that the rim surrounds is circular for $d=2 \mathrm{~mm}$ or $d=4 \mathrm{~mm}$ and deforms to become bean-shaped for $d=8 \mathrm{~mm}$. A sequence of images showing the rim 
dynamics for $d=8 \mathrm{~mm}$ is reported in Figure S2 (see Supplementary Material). We measured the oscillation frequencies of the rim for the different diameters by image processing using Fast Fourier Transform. At the same time, for the same volume flow rate, the frequency of the waves travelling in the downstream direction was determined by measuring the variations of the film thickness using CCI at a point far upstream of the perforation. For $Q_{2} / Q_{1}=0$, the dominant oscillation frequency of the rim (mode of highest energy) coincides with the frequency of the Kapitza waves travelling in the upstream region. The rim oscillation frequency is equal to 29 $\mathrm{Hz}$ for $d=4 \mathrm{~mm}, t=1 \mathrm{~mm}, \mathrm{Ka}=348$ and $\mathrm{Re}=31$. For $Q_{2} / Q_{1}=1$, the frequencies are of the same order but do not coincide.

It should be noted that the general wave pattern may be complicated by waves travelling in the upstream direction: as the rim bounces back in the upstream direction and impinges the perforation edge, it creates a train of circular waves (similarly to the waves generated by a drop impacting on a liquid surface) that propagate in the opposite direction of the flow and decay due to viscous effects.

We also studied the effect of plate thickness at fixed perforation diameter (see Figure S3 of the Supplementary Material): as the plate thickness is increased, the amount of liquid flowing along the inner surface of the perforation increases, the quantity of liquid discharged at the bottom edge of the perforation increases and the film thickness in the wake of the perforation is greater.

\section{Drops and liquid columns}

For large perforation diameters $(d=10-16 \mathrm{~mm})$ with one face supply, the suspended liquid rim destabilizes and forms drops or liquid columns (or jets). This mode is not observed with $55 \mathrm{wt} \%$ glycerin solution. Similar flow patterns have been reported for film flow on corrugated sheet with $10 \mathrm{~mm}$ perforations ${ }^{4}$, for film flow on a plane plate with a large rectangular window ${ }^{14}$ and for flow between horizontal circular tube ${ }^{18}$. The rim destabilization is attributed 
to Rayleigh-Taylor instability ${ }^{34,35}$. The so-called critical Taylor wavelength is given by $\lambda=$ $2 \pi(\sigma / \rho g)^{1 / 2} \cdot \lambda$ is equal to $10 \mathrm{~mm}$ for propan-2-ol and drops/columns are actually observed for perforation diameter $d \geq 10 \mathrm{~mm}$. For the present perforation diameter range $(d=10-$ $16 \mathrm{~mm}$ ), there is only one drop departure-site. Dripping proceeds as follows: a drop grows from the rim, elongates due to the gravity and contacts the bottom edge of the perforation (Figure 4c). At the same time, a liquid neck forms between the drop and the suspended rim. The drop drains on the bottom edge of the perforation. The neck shrinks until pinch-off and the detached drop leaves behind a liquid thread that recedes to the rim.

Dripping is not periodic. The intermittency is explained by the curvature of the perforation (as compared to a rectangular window ${ }^{14}$ ): the liquid tends to drain around the perforation instead of flowing straight down, the volume flow rate entering the pendant drop, is therefore irregular and the departure-site moves on the rim. For the same reason, for the largest diameters, the rim forms intermittently drops and liquid columns. When the volume flow entering the drop/column is lower, gravity and capillary effects dominate, and dripping is promoted. When the volume flow and the associated momentum flux are higher, inertia competes with gravity and capillary effects, and liquid jetting is promoted ${ }^{34}$.

\section{$\underline{\text { Pendant sheet }}$}

For large perforation diameters $(d=10-16 \mathrm{~mm})$ with two face supply and equal flow rates, the curtain mode is preceded by the formation of a stable liquid sheet that partially close the perforation. This mode is also observed for one-face supply with $55 \mathrm{wt} \%$ glycerin mixture. (instead of the drop/column mode). The bottom of the sheet is bounded by a cylindrical-shaped rim (see Figure 4d), which oscillates slightly in the vertical direction. The oscillation frequency is equal to $14 \mathrm{~Hz}$ for the conditions of Figure $4 \mathrm{~d}$. For the greatest perforation diameters, the rim undergoes the Plateau-Rayleigh instability and appears wavy (see the bead-on-a-string structure in Figure 4d). We also detect stationary capillary waves on the pendant sheet. Similar 
waves are observed just beyond the curtain transition. In the latter case, the waves are more visible: they are characterized in the discussion section for the curtain mode.

\section{Curtain transition and just beyond}

With further increase in flow rate, the fluid film fills entirely the perforation forming a thin liquid curtain, as shown in Figure 5. For one face supply, we clearly observe the transfer of liquid from the frontside to the backside of the plate. However, the flow pattern on the rear side differs from that before the curtain transition: the liquid now leaks from the bottom edge of the perforation in the form of a single rivulet.

The liquid curtain exhibits a stationary field of 2D capillary waves (see Figure 5bcd). The waves appear in the form of dark and bright horizontal stripes by shadowgraphy. The stripes are straight for $d=2-8 \mathrm{~mm}$. Transverse (y-direction) distortions of the 2D waves arise for $d=10-16 \mathrm{~mm}$

Figure 6 presents the free surface profile of the liquid film along $y=0$ for $Q_{2} / Q_{1}=1$ and $d=8 \mathrm{~mm}$, as deduced from film thickness measurements. Measurements were performed upstream of the perforation (supported film), within the perforation (suspended) and downstream of the perforation (supported). The free surface profile upstream and downstream of the perforation are measured only on one face and duplicated for clarity on the other side of the plate assuming symmetry. As already observed below the curtain transition, the perforation is topped with a stationary capillary ridge. The curtain free surface profile (within the perforation) exhibits standing waves. According to the literature ${ }^{36,37}$, two kinds of waves can propagate on a curtain: varicose waves (symmetric mode) corresponding to thickness modulation and sinuous waves (antisymmetric mode) corresponding to modulation in $\mathrm{z}$ direction of the curtain median position ${ }^{38}$. Figure 6 shows that the standing waves on the curtain are varicose. A curtain of viscous liquid is actually expected to be stable with respect to temporally as well as spatially changing varicose disturbances ${ }^{37}$. 
Since the pattern appears immobile in the laboratory's reference frame, it means that the wave speed is opposite to the local curtain speed. On the curtain, the wave amplitude decreases rapidly with distance from the bottom edge of the perforation (in the upstream direction). This trend is consistent with the exponential decrease due to viscous damping established by $\operatorname{Lin}^{37}$. Then, the transition from the suspended film to the supported film results in an abrupt increase in the film thickness downstream of the perforation bottom edge. Superimposed to this phenomenon, there is a ridge right downstream of the perforation. This feature, called inertial ridge, is also observed right downstream of a step-out or trench ${ }^{22}$. The present experimental results exhibit the same features (ridges upstream and downstream of the perforation, standing varicose waves on the curtain) as the simulation results reported by Xie et al. ${ }^{17}$ for liquid films flowing over a rectangular open window with two face supply $\left(Q_{2} / Q_{1}=1\right)$.

\section{Hysteresis}

When the volume flow rate is decreased from $Q_{1}^{c r}$, the film flow remains in the curtain mode for values of $Q_{1}$ much lower than $Q_{1}^{c r}$ : the curtain transition is thus hysteretic as already noted by $\mathrm{Hu} \& \mathrm{Jacobi}^{18}$ and by Xie et $a l .{ }^{14}$.

We further investigate this phenomenon with propan-2-ol for $Q_{2} / Q_{1}=1$ and $Q_{2} / Q_{1}=0$. In order to determine the width of the hysteresis, the volume flow rate is first increased up to $Q_{1}^{c r}$ to reach the curtain mode and then gradually reduced until the break up of the curtain is observed. It should be noted that right before the rupture, the curtain is affected by vibrations in z-direction: they are probably associated with the antisymmetrical mode of the curtain (sinuous waves).

It appears that for perforation diameter $d=6-16 \mathrm{~mm}$ and plate thickness $t=1-1.5 \mathrm{~mm}$, the Reynolds number of the film flow at the curtain rupture is equal to about 6 for $Q_{2} / Q_{1}=1$ and lies between 5 and 11 for $Q_{2} / Q_{1}=0$. This is significantly lower than the Reynolds number at the curtain transition which ranges typically between 20 and 50 for propan-2-ol. Moreover, 
for $d=2-4 \mathrm{~mm}$ and $t=1-1.5 \mathrm{~mm}$, the curtain maintains even when the volume flow rate vanishes.

Last, we observed that for a given flow rate (lower than $Q_{1}^{c r}$ ), the height of the capillary ridge upstream of the perforation is lower in the curtain mode than when the film flows around the perforation without filling it. As an example, for $t=1 \mathrm{~mm}, d=4 \mathrm{~mm}$, one face supply and $\operatorname{Re}=18$, we found that the ridge height in the curtain mode is $24 \%$ lower.

\section{Parametric study}

Since the curtain transition is associated with profound modifications of the flow pattern on the front side and backside of the plate, we expect that the same phenomenon, when occurring in an actual distillation column, should significantly affect the liquid redistribution, the pressure drop and the mass transfer. To trigger the curtain mode or, on the contrary, to avoid it, it is helpful to know the Reynolds number at the curtain transition $\left(\mathrm{Re}_{c r}\right)$. We set up a parametric study to examine the effect of perforation dimensions, flow rate ratio, and liquid type on $\operatorname{Re}_{c r}$.

\section{Influence of perforation dimensions}

We examine the effect of perforation diameter $(d)$ and plate thickness $(t)$ on $\operatorname{Re}_{c r}$ for one face supply $\left(Q_{2} / Q_{1}=0\right)$ and for two face supply with equal volume flow rates $\left(Q_{1} / Q_{2}=1\right)$. Experiments are carried out with propan-2-ol. It should be noted that for $d=2 \mathrm{~mm}$ and $t=$ $1.5 \mathrm{~mm}$, the curtain transition is very sensitive to parasitic vibrations and the determination of $\operatorname{Re}_{c r}$ requires a lot of care.

Figure 7 presents the variations of $\mathrm{Re}_{c r}$ as a function of the perforation diameter rescaled by the capillary length $\left(d / l_{c}\right)$. For both supply conditions, $\operatorname{Re}_{c r}$ increases with $d$ as long as $d \leq 6$ $\mathrm{mm}$. For $t=1 \mathrm{~mm}$ and $t=1.5 \mathrm{~mm}, \mathrm{Re}_{c r}$ is more or less on a plateau for $d \geq 6 \mathrm{~mm}$. For $t=$ $0.5 \mathrm{~mm}, \mathrm{Re}_{c r}$ significantly decreases from its maximum value reached at $d \cong 6 \mathrm{~mm}$, before arriving at a plateau. This decrease is attributed to the formation of liquid columns or pendant 
sheets (observed prior to the curtain transition for large perforation diameters) that helps to transit to curtain.

The increasing trend found at small perforation diameters is in line with the data reported by Xie et al. ${ }^{14}$ for rectangular open windows with streamwise length ranging from $5 \mathrm{~mm}$ to $7 \mathrm{~mm}$ and fixed spanwise width of $28 \mathrm{~mm}$. Unfortunately, Xie et al. ${ }^{14}$ do not report $\operatorname{Re}_{c r}$ data for windows of greater streamwise length. The presence of a plateau at large perforation diameters is consistent with Eq. (1) established in the problem description.

At fixed perforation diameter, $\operatorname{Re}_{c r}$ is significantly greater for $Q_{2} / Q_{1}=0$ than for $Q_{1} / Q_{2}=$ 1. In both cases, the film inertia required to overcome the surface tension forces and generate the curtain is roughly the same. However, in the former case, the momentum is solely brought by $Q_{1}$. In the latter, momentum is provided equally by $Q_{1}$ and $Q_{2}$.

For $Q_{2} / Q_{1}=0$, at given value of $d, \operatorname{Re}_{c r}$ increases significantly with the plate thickness. This phenomenon can be explained with one of the mechanisms responsible for the so-called teapot effect $^{39}$. At the top edge of the perforation (corresponding to the lip of the plate in Kistler \& Scriven's analysis ${ }^{39}$ ), the liquid flow is deflected from vertical direction toward the horizontal direction (parallel to the inner surface of the perforation). Since the liquid wets the inner surface of the perforation, this deflection increases with the plate thickness and "delay" the curtain transition: higher inertia forces are required for the fluid film to form a curtain. The effect of $t$ on the plateau value is less pronounced for $Q_{1} / Q_{2}=1$. Indeed, on each face, the film flow experienced only half of the plate thickness. Furthermore, the symmetry of the system prevents the liquid to flow from one face to the other.

\section{Influence of the flow rate ratio $Q_{2} / Q_{1}$}

The flow rate ratio in a real corrugated sheet packing lies typically between the two limiting cases $Q_{2} / Q_{1}=0$ and $Q_{2} / Q_{1}=1$ (with $Q_{2} \leq Q_{1}$ ). We thus examine the effect of the fluid flow ratio on the curtain Reynolds number. Two different values of the perforation diameter 
are investigated, i.e. $d=4 \mathrm{~mm}$ and $d=8 \mathrm{~mm}$. The plate thickness is equal to $t=1 \mathrm{~mm}$ in both cases. The tested liquid is propan-2-ol.

The variations of $\operatorname{Re}_{c r}$ are represented as a function of $Q_{1} / Q_{2}$ instead of $Q_{2} / Q_{1}$ for a better rendering (see Figure 8). It appears that the curves associated with $d=4 \mathrm{~mm}$ and $d=8 \mathrm{~mm}$ look the same except that the latter is shifted away from the former toward higher Reynolds number values. Irrespective of the perforation diameter, we observe that $\operatorname{Re}_{c r}$ grows significantly in the range $1 \leq Q_{1} / Q_{2} \leq 3$, and stabilizes to a plateau when $Q_{1} / Q_{2} \geq 3$.

\section{Influence of liquid type}

We examine the effect of the liquid type on the curtain Reynolds number. Experiments are carried out with four different liquids covering a large range of Kapitza numbers, i.e. propan2-ol $(\mathrm{Ka}=348), 55 \mathrm{wt} \%$ glycerin aqueous solution $(\mathrm{Ka}=245), 25 \mathrm{wt} \%$ glycerin aqueous solution $(\mathrm{Ka}=1470)$ and pure water $(\mathrm{Ka}=3920)$.

Figure 9 presents the variations of $\mathrm{Re}_{c r}$ as a function of the perforation diameter rescaled by the capillary length, for one face supply and for two face supply with equal volume flow rates. Regardless of the Kapitza number value, the shape of the curve $\operatorname{Re}_{c r}$ versus $d / l_{c}$ is essentially the same: $\mathrm{Re}_{c r}$ first increases with $d$, reaches a maximum, then eventually decreases (for $\mathrm{Ka}=$ 1470 and $\mathrm{Ka}=3920$ ) and finally stabilizes to a plateau. The greater the Kapitza number, the greater the width of the increasing phase and the steepest the slope of the curve in this phase. Furthermore, the plateau value (reached at large values of $d / l_{c}$ ) increases with the Kapitza number. This trend is consistent with the scaling law of Eq. (1) established in the problem description. 


\section{Discussion}

\section{Model for curtain transition}

We compared our experimental results with the empirical correlations of $\mathrm{Hu} \& \mathrm{Jacobi}^{18}$ and Xie et al. ${ }^{14}$ mentioned in the introduction. It appears that these correlations only provide a rough estimate of the curtain transition (see annex A4 in Supplementary Material). Indeed, they are specific to the system with which they have been established (large rectangular window with one face supply ${ }^{14}$ or spaced horizontal tubes ${ }^{18}$ ), and they do not explain the physics of the phenomena.

We propose to establish a criterion for the curtain formation from a macroscopic momentum balance on the upstream portion of the rim, near the stagnation point. The details of the derivation are given in annex A5 (see Supplementary Material).

This approach revisits a model first proposed by Hartley and Murgatroyd ${ }^{40}$ for the break-up of thin liquid films flowing over solid surfaces (criterion for the formation of dry patches). At the onset of curtain formation in a perforation of large diameter, we expect that the rim is essentially subjected to two forces: the surface tension force that resists curtain formation and the fluid inertia that drives this transition. In order to express the surface tension force, we idealize the film profile as follows: we consider that the film profile is flat on both sides of the plate and axisymmetric with respect to the perforation axis (see Figure 10).

We denote $R$ the radius of the hole surrounded by the rim. The surface tension force per unit circumference of the rim acting in the radial direction $\left(f_{\sigma}\right)$ is given by:

$$
f_{\sigma}=\sigma\left(1-\frac{t}{R}-\frac{\delta_{N u}\left(Q_{1}\right)}{R}-\frac{\delta_{N u}\left(Q_{2}\right)}{R}\right)
$$

$f_{\sigma}$ is an increasing function of $R$ and is maximal when $R=d / 2$. As a first approximation, let us consider that $f_{\sigma}=f_{\sigma}(R / 2)$ at the curtain transition. We keep in mind that this assumption 
tends to overestimate the capillary force. Therefore, the inertial force required to drive the curtain transition should be overrated as well.

$f_{\sigma}$ cancels for $d=t+\delta_{N u}\left(Q_{1}\right)+\delta_{N u}\left(Q_{2}\right)$ and spontaneous curtain formation (due to capillary action only) is expected for perforation diameter $d \leq t+\delta_{N u}\left(Q_{1}\right)+\delta_{N u}\left(Q_{2}\right) . f_{\sigma}$ opposes the formation of the liquid curtain for $d \geq t+\delta_{N u}\left(Q_{1}\right)+\delta_{N u}\left(Q_{2}\right)$.

The $\mathrm{x}$-component of the momentum net flux entering the rim close to the stagnation point reads (per unit length of rim):

$$
f_{u}=\int_{0}^{\delta_{N u}\left(Q_{1}\right)} \rho u_{x}^{2}(y) d y+\int_{0}^{\delta_{N u}\left(Q_{2}\right)} \rho u_{x}^{2}(y) d y
$$

where $u_{x}(y)$ is the Nusselt velocity profile. After substitution and integration, we find:

$$
f_{u}=\frac{2}{15} \times \frac{\rho g^{2}}{v^{2}}\left(\left(\delta_{N u}\left(Q_{1}\right)\right)^{5}+\left(\delta_{N u}\left(Q_{2}\right)\right)^{5}\right)
$$

The curtain forms when the momentum flux balances the maximal surface tension force. When expressed with the dimensionless parameters determined in the problem description, the criterion for the curtain formation reads

$$
\operatorname{Re}_{c r}=\frac{1}{3}\left(\frac{15 \mathrm{Ka}}{1+\left(\frac{Q_{2}}{Q_{1}}\right)^{5 / 3}}\left(1-\frac{t}{d}-3^{1 / 3} \mathrm{Ka}^{-1 / 2}\left(\frac{d}{l_{c}}\right)^{-1} \mathrm{Re}_{c r}^{1 / 3}\left(1+\left(\frac{Q_{2}}{Q_{1}}\right)^{1 / 3}\right)\right)\right)^{3 / 5}
$$

Figure 11 shows that Eq. (4) is in good agreement with the experimental data obtained for two face supply of equal flow rates. We emphasize that the present model does not involve any ad hoc adjustable parameter. It can be seen that the model overestimates the curtain Reynolds number for one face supply. Eq. (4) predicts that the plateau value for the supply condition $\mathrm{Q}_{2} / \mathrm{Q}_{1}=0$ is $\left(2^{3 / 5}-1\right) \cong 50 \%$ higher than that for $\mathrm{Q}_{2} / \mathrm{Q}_{1}=1$. This difference is significantly greater than the $25 \%$ found experimentally. We expect that gravity effects (not accounted for by our simple model) promote the curtain transition and thus reduce the 
momentum flux otherwise required. For two face supply, the liquid rim on the inner surface of the perforation is drained by the film flow on both side of the plate. On the contrary, for one face supply, the rim is only drained on the front side. Subsequently, liquid tends to accumulate on the inner surface, close to the back side of the plate. Since the rim is thicker, gravity effects are enhanced. If we assume that the liquid rim has a size $(d / 2-R)$ of the order of the plate thickness, we find that the Bond number (which compares gravity to interfacial tension forces) is slightly lower than 1 .

The present model also predicts that for sufficiently small values of the perforation diameter (compared to the plate thickness, i.e. $d \leq t$ ), the hole within the liquid film is not thermodynamically stable. Consequently, the liquid should spontaneously fill the perforation by capillarity and the curtain Reynolds number should vanish. However, since the equilibrium contact angle is not zero, a minimum volume flow rate per unit width is practically required otherwise the contact line remains pinned on the edge of the perforation. We experimentally investigated the case $d=t=1 \mathrm{~mm}$ with propan-2-ol for one face and two face supply. We found that the curtain Reynolds number is equal to $\mathrm{Re}_{c r}=14$ and $\mathrm{Re}_{c r}=8$, respectively. But, when the curtain is formed, it maintains even when the volume flow rate vanishes.

We also compared our model to the experimental data obtained with various liquids for the supply condition $Q_{2} / Q_{1}=1$ (see annex A6 in Supplementary Material). It can be seen that the variations of $\mathrm{Re}_{c r}$ as a function of $d / l_{c}$ are well represented for the liquids characterized by a low Kapitza number. The agreement is less satisfactory for liquids with high Ka. However, it gives a good estimate of the plateau value reached at high perforation diameters.

Last, we used Eq. (4) to predict the curtain transition for a flat plate with $54^{\circ}$ inclination to horizontal fed with liquid nitrogen $\left(\mathrm{Ka}=4690\right.$ for $54^{\circ}$ inclination $)$, details are given in annex A7 (see Supplementary Material). We found that $\mathrm{Re}_{c r}=170$ for two face supply. This result gives a first estimate of the curtain threshold in a 500Y (gravity angle of $54^{\circ}$ ) type structured 
packing operating with liquid nitrogen. In these conditions, the liquid load would be of the order of $60 \mathrm{~m}^{3} \cdot \mathrm{m}^{-2} \cdot \mathrm{h}^{-1}$ and the holdup of $6 \%$. These results have to be validated on a real perforated corrugated sheet packing. We emphasize that the present work has been carried out on flat plates with a single perforation. Further comprehensive studies are needed to examine the effects of corrugations, location of the perforations (with respect to the crest of the corrugations) and optionally sheet microtexture on the curtain transition.

\section{Liquid behavior within and around the perforation in curtain mode}

Let us recall the main features of the liquid film free surface observed in the curtain mode (see Figure 6). Right upstream of the perforation, the supported liquid film exhibits a stationary capillary ridge. This ridge produces the capillary over-pressure required to push the liquid inside the perforation since the gravity that drives the film flow on the plate acts perpendicularly to the perforation inner surface ${ }^{21,32}$. Right downstream of the perforation, there is an inertial ridge, caused by an overshoot of the liquid film as it is deflected in the vertical direction by the step ${ }^{25}$. Within the perforation, the curtain free surface profile results from two superimposed phenomena, i.e. the stretching of the curtain due to the acceleration of the gravity and the excitation of varicose capillary waves that propagate upstream (in the liquid's reference frame). The capillary waves are excited by the impact of the liquid curtain on the bottom edge of the perforation. The pattern appears immobile in the laboratory's reference frame, indicating that the wave speed is opposite to the local curtain speed. Similar phenomena have already been reported by Ruschak ${ }^{41}$ for liquid films or jets entering a relatively large pool and more recently by Hancock and Bush for a laminar liquid jet impinging on a deep liquid reservoir ${ }^{42}$. According to Xie et al. ${ }^{17}$, the varicose waves induce strong generation of vorticity which is expected to enhance mass transfer. 
Let us further analyze the curtain behavior for $Q_{2} / Q_{1}=1$. We first omit the standing varicose waves and describe the variations of the curtain half-thickness $(h)$ by a simple free fall model. Expressing the mass conservation of the free-falling liquid between $x_{e}$ and $x$, we get

$$
h(x) \cong \frac{Q_{1}^{e}}{\left(\left(Q_{1}^{e} / h\left(x_{0}\right)\right)+2 g\left(x-x_{0}\right)\right)^{1 / 2}}
$$

for $x \geq x_{e} . Q_{1}^{e}$ is the volume flow rate per unit width at location $x_{e}$.

Eq. (5) is fitted to the experimental curtain profile of Figure 6, by adjusting the volume flow rate per unit width to an effective value $Q_{1}^{e}=0.65 \times Q_{1} . x_{e}$ is presently the highest measuring point within the perforation. Results are displayed in Figure 12a. We also fitted the experimental data obtained for a greater perforation diameter $d=12 \mathrm{~mm}$ (see Figure S6 in Supplementary Material) and found $Q_{1}^{e}=0.75 \times Q_{1}$. The difference between $Q_{1}^{e}$ and $Q_{1}$ is attributed to the significant deviation of the flow around the perforation that persists at the curtain transition. We expect that downstream of $x_{e}$, viscous effects negligibly affect the stretching of the curtain and cannot be responsible for the difference above mentioned. Indeed, in Figure $6, x_{e}$ is located $1.1 \mathrm{~mm}$ away from the perforation top edge $(2.3 \mathrm{~mm}$ for $d=12 \mathrm{~mm}$ in Figure S6), this distance is slightly greater that the "entrance" length ${ }^{24}$ of the order of $10 \times l_{v} \cong 0.9 \mathrm{~mm}$.

The velocity $\left(c_{v a r}\right)$ of the varicose waves propagating on a curtain of uniform thickness $(2 h)$ has been established by Taylor ${ }^{36}$ in the limit of small disturbance of the free surface and inviscid ambient gas:

$$
c_{v a r}^{2}=\left(\frac{\sigma}{\rho h}\right)(k h \tanh (k h))
$$

where $k$ is the wave number. Since the waves appear presently immobile in the laboratory's reference frame, the wave velocity should match the curtain local speed, i.e.

$$
c_{v a r}=\frac{Q_{1}^{e}}{h}
$$


Then, the wavelength $(\lambda)$ of the wave that stands on the curtain with given local thickness $(2 h)$ can be deduced from Eq. (6-7). By solving Eq. (5-7), we obtain the theoretical wavelength $(\lambda)$ of the standing wave at a given position $(x)$ on the curtain. The wavelength varies along the curtain since the curtain thickness $(2 h)$ decreases as $x$ increases.

To validate these findings, let us return to the data of Figure 6 . The standing varicose wave can be isolated by subtracting the pure stretching curve to the experimental curtain profile (see Figure S7 in Supplementary Material). The local wavelength of the varicose wave is measured between successive peaks along the curtain. These values are reported in Figure $12 \mathrm{~b}$ where $x$ corresponds to the midpoint between successive peaks used to estimate the local wavelength. It can be seen that there is a very good agreement between the theoretical and the experimental values. This validates the matching assumption Eq. (7) and the picture to explain the curtain behavior.

Incidentally, we can estimate the damping length of the varicose wave for the conditions of Figure 6, i.e. $c_{v a r} /\left(8 \pi^{2} v / \lambda^{2}\right) \cong 2 \mathrm{~mm}$ where the denominator is the damping rate established by $\operatorname{Lin}^{37}$. This estimate is consistent with the observations.

We also deduce from Figure 12ab that the adjustment of $Q_{1}^{e}$ is relevant and should provide a good estimate of the real volume flow rate over the perforation. From this estimate and from the measured thickness profile (Figure 6), we can determine the variations of the local Weber number We $=\rho\left(Q_{1}^{e}\right)^{2} /(h \sigma)$ along the curtain. We find that We ranges between 0.4 at $x_{e}$ and 0.8 close to the bottom edge of the perforation. According to $\mathrm{Brown}^{24}$ and $\mathrm{Lin}^{37}$, a curtain that includes a domain with We $<1$ is unstable with respect to spatially growing sinuous disturbances propagating upstream. It appears that the curtain seems not affected by sinuous waves beyond the curtain transition. However, in the hysteresis loop, when the curtain still stands although the volume flow rate is significantly lower than the curtain flow rate $\left(Q_{c r}\right)$, the curtain is thinner and its rupture (when observed) seems to be triggered by growing sinuous 
waves. Indeed, at given wavelength, as the curtain thickness decreases, the velocity of the varicose waves becomes much smaller than the velocity of the sinuous waves. Subsequently, sinuous waves are expected to dominate.

\section{Conclusion}

We experimentally studied the local hydrodynamics of a liquid film flowing over a round hole perforation. Such topographies are typically found in the corrugated sheet packings used in distillation columns. Perforations are known to contribute to liquid phase redistribution and mass-transfer enhancement.

We first characterized the different flow patterns occurring on a singly perforated plate as a function of the Reynolds number of the film, for one face supply and two face supply with equal volume flow rates. At low values of the Reynolds number, the liquid film flow is deflected by the perforation and the liquid does not fill the perforation. An arch-shaped stationary capillary ridge forms at the (upstream) stagnation point and extends downstream of the perforation. As the Reynolds number increases, the apex of the capillary ridge shifts toward the perforation and a liquid rim grows within the perforation. Beyond a critical value of the Reynolds number, referred to as the curtain Reynolds number $\left(\operatorname{Re}_{c r}\right)$, the liquid entirely fills the perforation and forms a liquid curtain. The curtain exhibits stationary varicose capillary waves. The curtain transition is preceded by specific patterns that depend on the perforation diameter, i.e. oscillating rim, dripping drops and liquid columns, or pendant sheet (for increasing perforation diameter, respectively). The curtain transition is highly hysteretic: when Re is decreased from $\mathrm{Re}_{c r}$, the liquid curtain may persist within the perforation for Reynolds numbers well below $\mathrm{Re}_{c r}$.

We emphasize that the curtain transition occurs well above the onset of liquid transfer from the front side to the back side of the plate. The transfer starts with the formation of the liquid rim 
within the perforation. For one face supply, liquid transfer is clearly observed until and above the curtain transition.

We carefully examined the influence of perforation diameter, plate thickness, liquid type and volume flow rate ratio on the curtain Reynolds number. We found that (i) $\operatorname{Re}_{c r}$ increases with the perforation diameter, possibly goes through a maximum, and reaches a plateau for higher diameter values; (ii) $\mathrm{Re}_{c r}$ increases with the plate thickness as a consequence of the so-called teapot effect, this increase is more pronounced for one face supply; (iii) $\mathrm{Re}_{c r}$ increases with the Kapitza number (Ka) of the liquid and the plateau value of the curtain Reynolds number scales as $\mathrm{Ka}^{3 / 5}$; (iv) $\mathrm{Re}_{c r}$ (defined with the volume flow rate on the front side of the plate) decreases as the volume flow rate on the back side increases.

We propose a new criterion for the curtain formation. This criterion was derived from a macroscopic momentum balance on the rim near the stagnation point. We considered that the rim is essentially subjected to two forces: the surface tension force that resists the curtain formation and the fluid inertia that drive the transition. This model adequately describes the effect of perforation diameter, Kapitza number and flow rate ratio on the curtain Reynolds number.

Finally, we showed that the dynamics of a curtain within a perforation results from two superimposed phenomena: the stretching of the curtain due to the acceleration of the gravity and the excitation of varicose waves consequently to the impact of the curtain on the bottom edge of the perforation. The stretching is well described by a simple free fall model. We found that the wavelength of the varicose wave is selected such that the velocity of the waves both satisfies Taylor's dispersion relation and matches the curtain local speed. As a consequence, the varicose wave appears immobile in the plate reference frame. The varicose waves are expected to enhance mass-transfer through the liquid curtain. 
In the future, we plan to further investigate the curtain mode, i.e. by quantifying the fluid flow rate transferred through a perforation from one side of the plate to the other, by performing velocimetry to determine the velocity and vorticity fields within the supported and the suspended liquid film.

\section{Acknowledgments}

This research was supported by Air Liquide Research \& Development and by Association Nationale de la Recherche et de la Technologie ANRT (CONVENTION CIFRE $\mathrm{N}^{\circ}$ 2017/1472). The authors express their gratitude to Sebastien Gauthier and Frederic Lesage for their technical contribution to the project. The authors acknowledge Jamila El Bekri for the contact angle measurements, Nathalie Ruscassier for the surface roughness measurements, and Prof. Marie-Laurence Giorgi for her kind help with the FFT analysis.

\section{References}

1. Spiegel L, Meier W. Distillation columns with structured packings in the next decade. Chem Eng Res Des. 2003;81(1):39-47.

2. Pavlenko AN, Pecherkin NI, Zhukov VE, Meski G, Houghton P. Overview of methods to control the liquid distribution in distillation columns with structured packing: Improving separation efficiency. Renew Sustain Energy Rev. 2020;132,110092,1-11.

3. Alekseenko S V., Markovich DM, Evseev AR, Bobylev A V., Tarasov B V., Karsten VM. Experimental study of liquid distribution in a column with a structured packing. Theor Found Chem Eng. 2007;41(4):417-423.

4. Pavlenko AN, Volodin OA, Surtaev AS. Hydrodynamics in falling liquid films on surfaces with complex geometry. Appl Therm Eng. 2017;114:1265-1274.

5. Zhao L, Cerro RL. Experimental characterization of viscous film flows over complex surfaces. Int J Multiph Flow. 1992;18(4):495-516. 
6. Shetty S, Cerro RL. Flow of a thin film over a periodic surface. Int J Multiph Flow. 1993;19(6):1013-1027.

7. Vlachogiannis M, Bontozoglou V. Experiments on laminar film flow along a periodic wall. J Fluid Mech. 2002;457:133-156.

8. Trifonov YY. Stability of a viscous liquid film flowing down a periodic surface. Int $J$ Multiph Flow. 2007;33(11):1186-1204.

9. Pollak T, Aksel N. Crucial flow stabilization and multiple instability branches of gravity-driven films over topography. Phys Fluids. 2013;25(2), 024103.

10. Schörner M, Reck D, Aksel N. Does the topography's specific shape matter in general for the stability of film flows? Phys Fluids. 2015;27(4), 042103.

11. Cao Z, Vlachogiannis M, Bontozoglou V. Experimental evidence for a short-wave global mode in film flow along periodic corrugations. J Fluid Mech. 2013;718(May):304-320.

12. Dietze GF. Effect of wall corrugations on scalar transfer to a wavy falling liquid film. J Fluid Mech. 2019;859,1098-1128.

13. Negny S, Meyer M, Prevost M. Study of a laminar falling film flowing over a wavy wall column: Part II. Experimental validation of hydrodynamic model. Int J Heat Mass Transf. 2001;44(11):2147-2154.

14. Xie H, Hu J, Wang C, Dai G. Liquid flow transition and confined free film formation on a vertical plate with an open window. Exp Therm Fluid Sci. 2018;92(July 2017):174-183.

15. Hu J, Liu J, Yu J, Dai G. CO2 absorption into highly concentrated DEA solution flowing over a vertical plate with rectangular windows. Int J Greenh Gas Control. 2013;19:13-18.

16. $\mathrm{Hu}$ J, Yang X, Yu J, Dai G. Carbon dioxide (CO2) absorption and interfacial mass 
transfer across vertically confined free liquid film-a numerical investigation. Chem Eng Process Process Intensif. 2017;111:46-56.

17. Xie H, Hu J, Dai G. Numerical simulation on flow behavior of twin-liquid films over a vertical plate with an open window. AIChE J. 2018;64(4):1458-1468.

18. Hu X, Jacobi AM. The intertube falling film: Part 1-flow characteristics, mode transitions, and hysteresis. J Heat Transfer. 1996;118(3):616-625.

19. Aksel N, Schörner M. Films over topography: from creeping flow to linear stability, theory, and experiments, a review. Acta Mech. 2018;229(4):1453-1482.

20. Stillwagon LE, Larson RG. Leveling of thin films over uneven substrates during spin coating. Phys Fluids A. 1990;2(11):1937-1944.

21. Mazouchi A, Homsy GM. Free surfaces stokes flow over topography. Phys Fluids. $2001 ; 13(10): 2751-2761$.

22. Bontozoglou V, Serifi K. Falling film flow along steep two-dimensional topography: The effect of inertia. Int J Multiph Flow. 2008;34(8):734-747.

23. Nusselt W. Die Oberflächenkondensation Des Wasserdampfes. Zeitschrift des Vereines Deutscher Ingenieure. 1916;60:541-546

24. Brown DR. A study of the behaviour of a thin sheet of moving liquid. J Fluid Mech. 1961;10(2):297-305.

25. Culick FEC. Comments on a ruptured soap film. J Appl Phys. 1960;31(6):1128-1129.

26. Paez S, Contreras M. Densities and Viscosities of Binary Mixtures of 1-Propanol and 2-Propanol with Acetonitrile. J Chem Eng Data. 1989;34(4):455-459.

27. Vazquez G, Alvarez E, Navaza JM. Surface Tension of Alcohol + Water from 20 to 50 ${ }^{\circ}$ C. J Chem Eng Data. 1995;40(3):611-614.

28. Segur J. Physical properties of glycerol and its solutions. In Minor CS, Dalton NN. Glycerol. New York: Reinhold Publishing Corporation, 1953:238-334. 
29. Korson L, Drost-Hansen W, Millero FJ. Viscosity of water at various temperatures. $J$ Phys Chem. 1969;73(1):34-39.

30. Kofman N, Mergui S, Ruyer-Quil C. Characteristics of solitary waves on a falling liquid film sheared by a turbulent counter-current gas flow. Int J Multiph Flow. 2017;95:22-34.

31. Dietze GF, Al-Sibai F, Kneer R. Experimental study of flow separation in laminar falling liquid films. J Fluid Mech. 2009;637:73-104.

32. KALLIADASIS S, HOMSY GM. Stability of free-surface thin-film flows over topography. J Fluid Mech. 2001;448:387-410.

33. Kapitza PL. Wave Flow of Thin Layers of a Viscous Fluid, Collected Papers of P.L. Kapitza (1965), Pages 662-689. Pergamon (Oxford); 1948.

34. $\mathrm{Hu}$ X, Jacobi AM. Departure-site spacing for liquid droplets and jets falling between horizontal circular tubes. Exp Therm Fluid Sci. 1998;16,322-331.

35. Yung D, Lorenz, J J, Ganic EN. Vapor/Liquid Interaction and Entrapment in Failing Film. J Heat Transf Asme. 2016;102(78):20-25

36. Taylor G. The Dynamics of Thin Sheets of Fluid. II. Proc R Soc A Math Phys Eng Sci. $1959 ; 253(1274): 313-321$.

37. Lin SP. Stability of a viscous liquid curtain. J Fluid Mech. 1981;104,111-118.

38. Le Grand-Piteira N, Brunet P, Lebon L, Limat L. Propagating wave pattern on a falling liquid curtain. Phys Rev E - Stat Nonlinear, Soft Matter Phys. 2006;74(2):1-8.

39. Kistler SF, Scriven LE. The Teapot Effect: Sheet-Forming Flows With Deflection, Wetting and Hysteresis. J Fluid Mech. 1994;263:19-62.

40. Hartley DE, Murgatroyd W. Criteria for the break-up of thin liquid layers flowing isothermally over solid surfaces. Int J Heat Mass Transf. 1964;7,1003-1015.

41 Ruschak K. Flow of a falling film into a pool. AIChE J. 1978;24(4):705-709. 
42. Hancock MJ, Bush JWM. Fluid pipes. J Fluid Mech. 2002;466:285-304. 


\section{Table 1}

\begin{tabular}{|c|c|c|c|c|c|c|}
\hline Liquid & $\begin{array}{c}\rho \\
(\text { kg.m } \\
\end{array}$ & $\begin{array}{c}\mu \\
\text { (mPa.s) } \\
\end{array}$ & $\begin{array}{c}\sigma \\
\left(\mathrm{mN} \cdot \mathrm{m}^{-1}\right)\end{array}$ & $\begin{array}{c}\theta \\
\left({ }^{\circ}\right) \\
\end{array}$ & $\mathrm{Ka}$ & Re range \\
\hline Propan-2-ol & $786^{\mathrm{a}}$ & $2.05^{\mathrm{b}}$ & $21^{\mathrm{c}}$ & $11-17^{\mathrm{a}}$ & 348 & $6-80$ \\
\hline $55 \mathrm{wt} \%$ glycerin & $1134^{\mathrm{a}}$ & $7.05^{\mathrm{d}}$ & $68^{\mathrm{d}}$ & $22-30^{a}$ & 245 & $2-35$ \\
\hline $25 \mathrm{wt} \%$ glycerin & $1056^{\mathrm{a}}$ & $1.87^{\mathrm{d}}$ & $71^{\mathrm{d}}$ & $23-35^{\mathrm{a}}$ & 1470 & $9-115$ \\
\hline Pure water & $997^{\mathrm{a}}$ & $0.891^{\mathrm{e}}$ & $72^{c}$ & $40-65^{a}$ & 3920 & $15-225$ \\
\hline
\end{tabular}


Figure 1
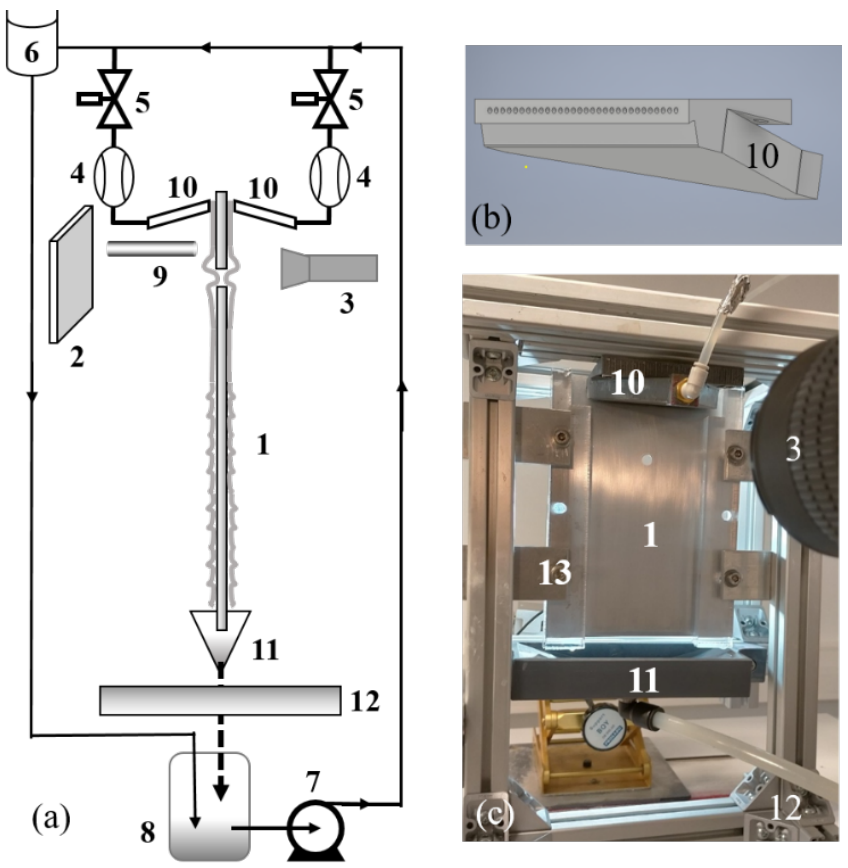
Figure 2

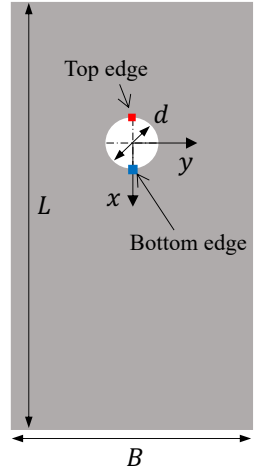

(a)

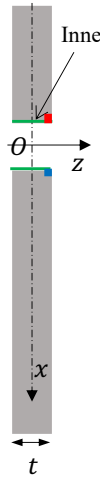

$\left(Q_{2} / Q_{1}=0\right)$

(b)

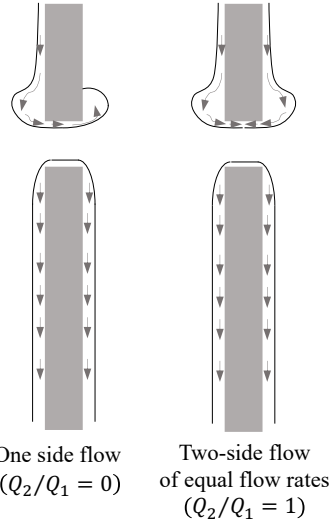

(c) 
Figure 3

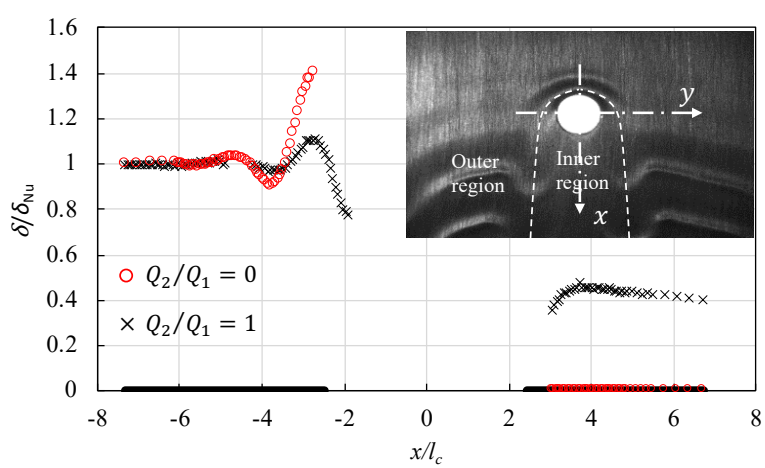


Figure 4
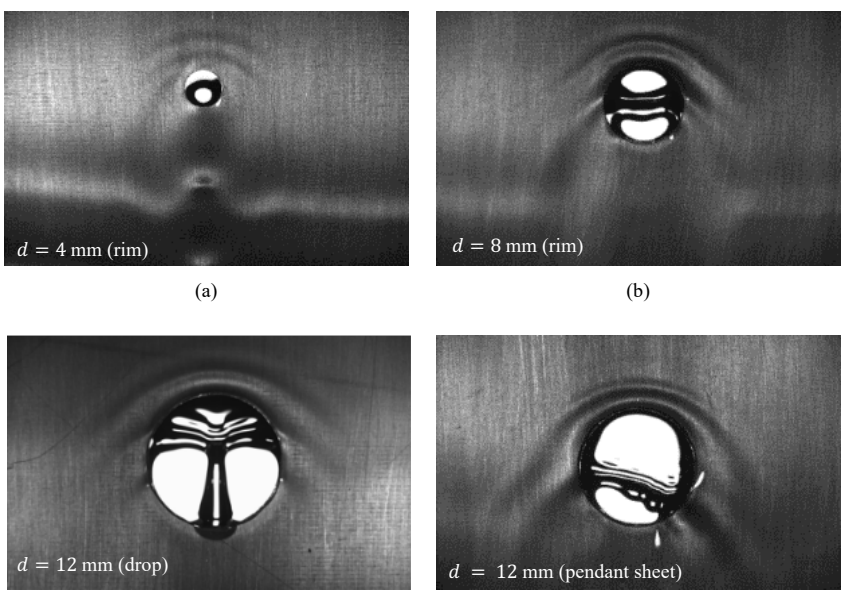

(c)

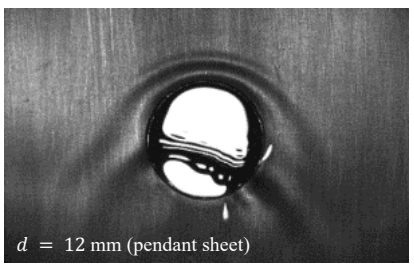

(d) 
Figure 5
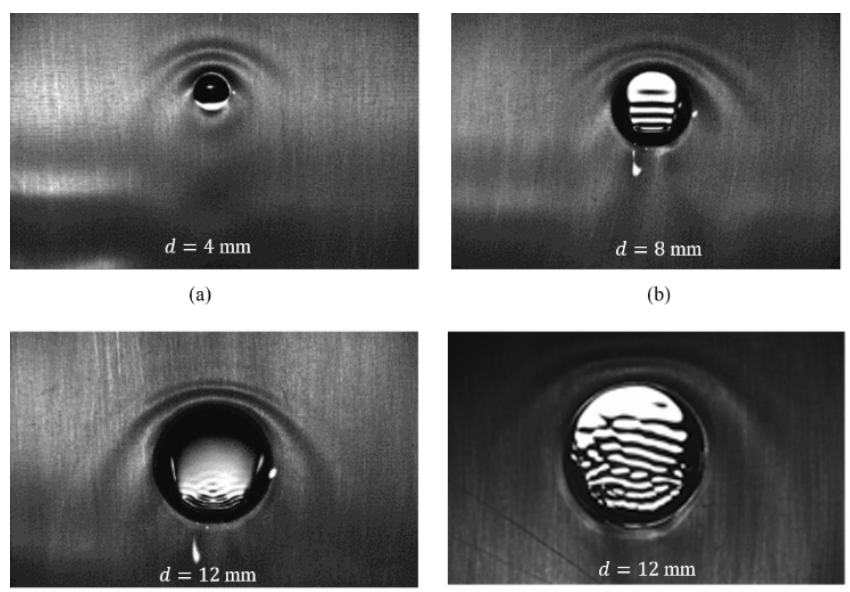

(c)

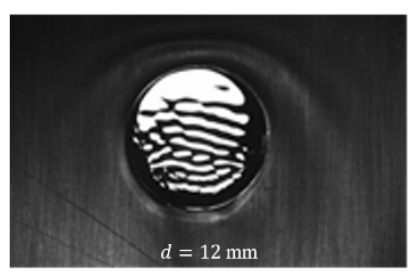

(d) 
Figure 6

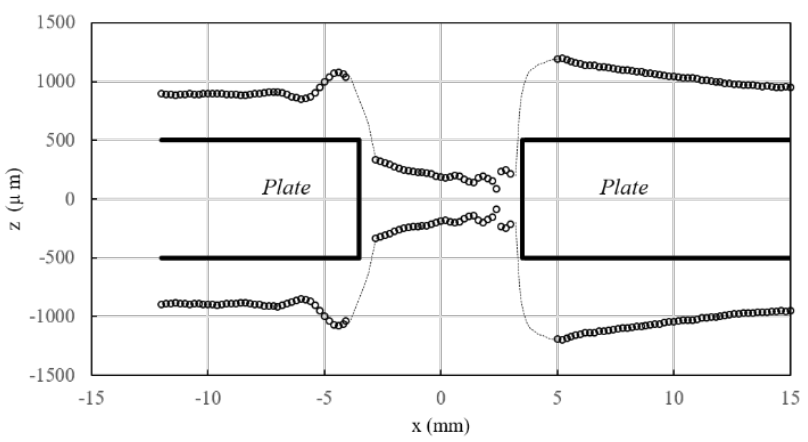


Figure 7

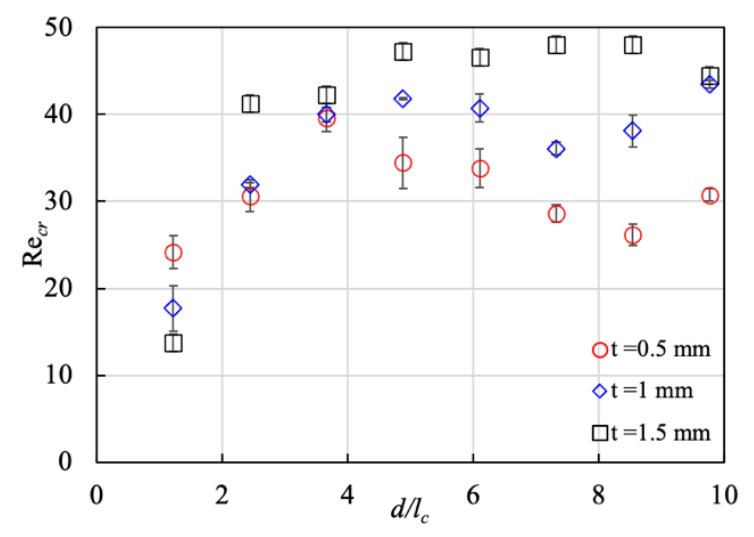

(a)

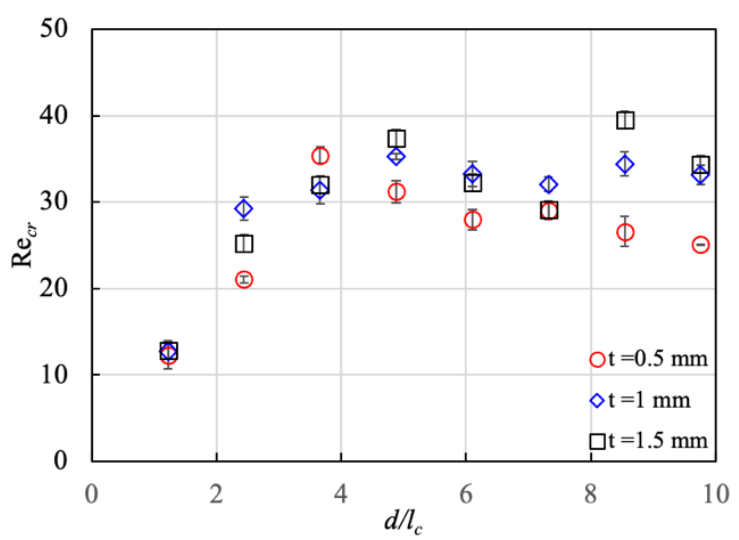

(b) 
Figure 8

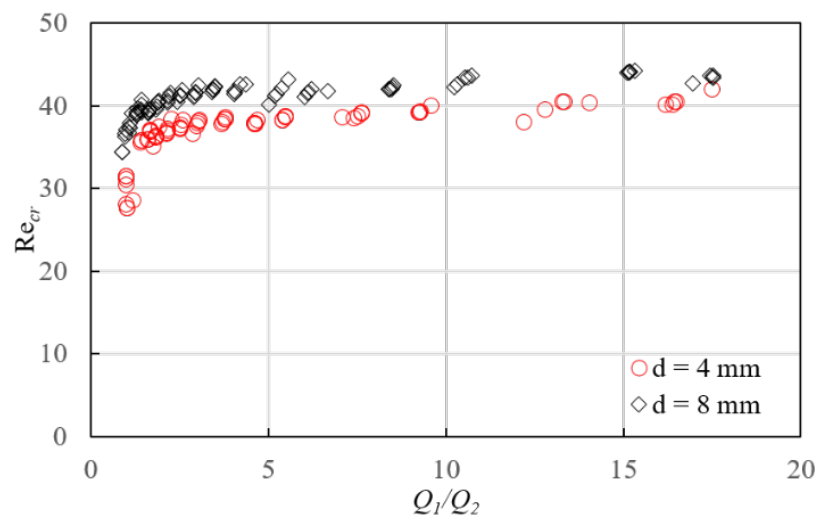


Figure 9

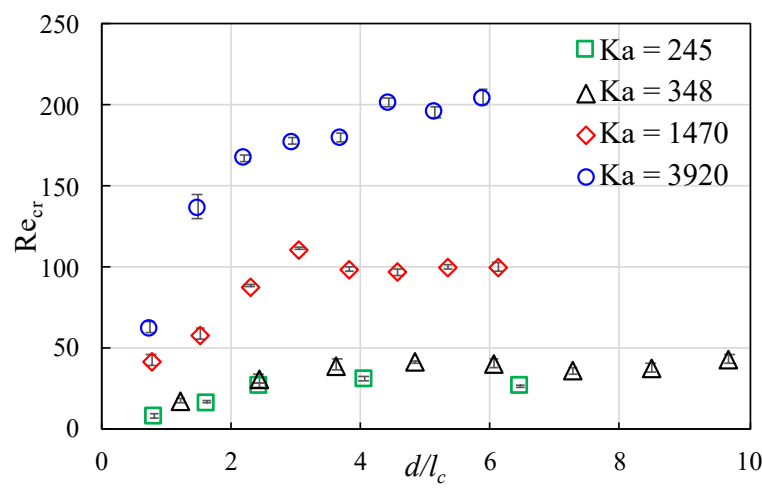

(a)

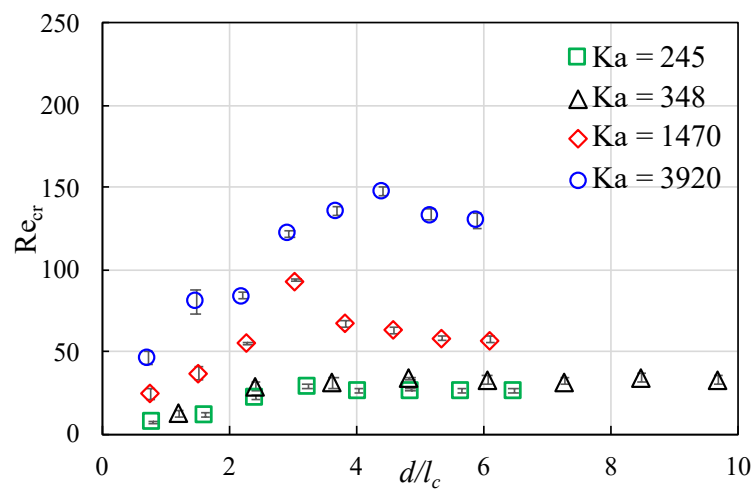

(b) 
Figure 10

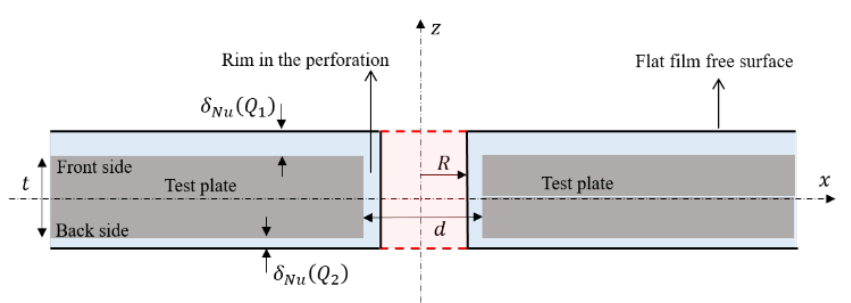


Figure 11

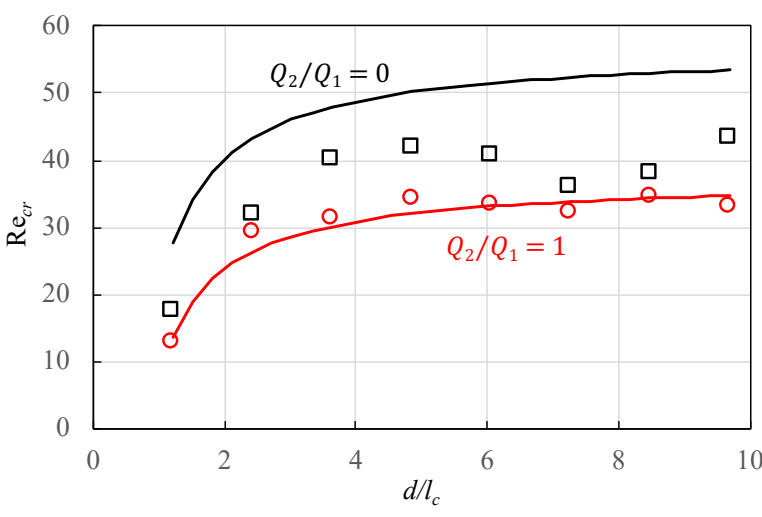

(a)

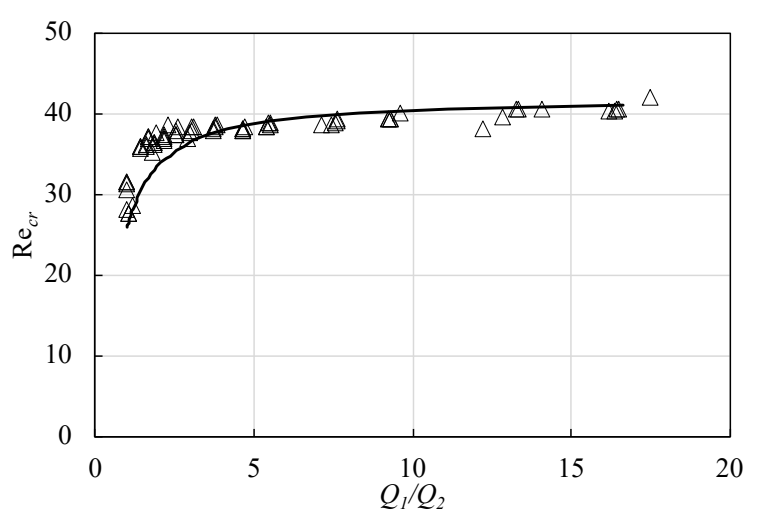

(b) 
Figure 12
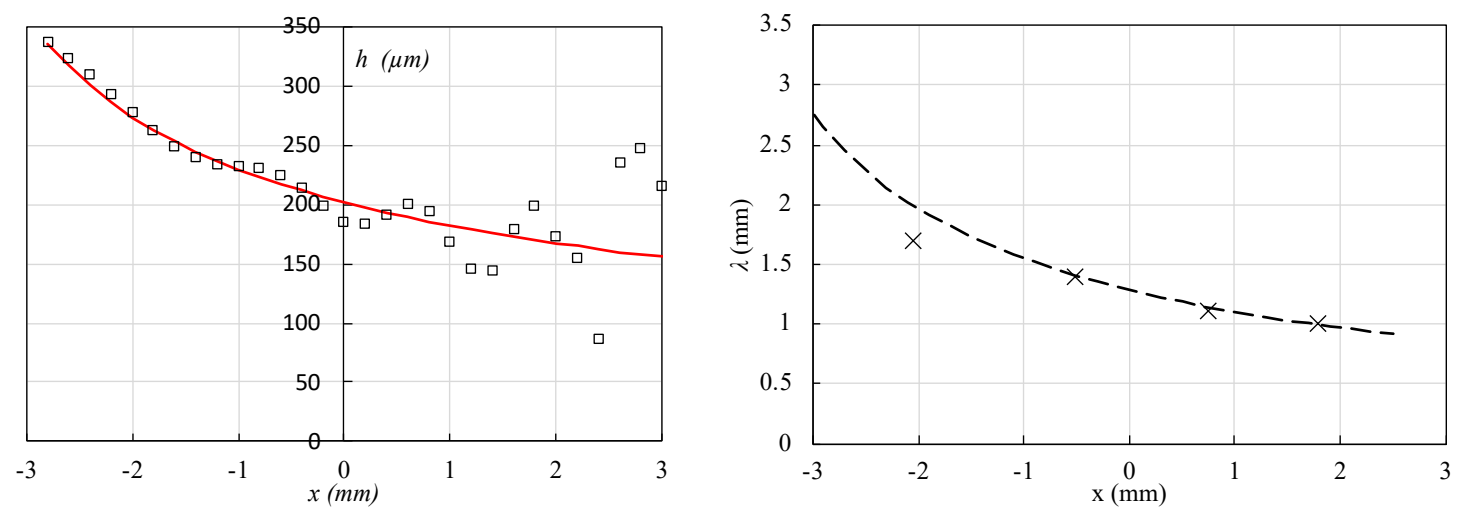


\section{List of figure captions}

Table 1. Physical properties (at $25^{\circ} \mathrm{C}$ ) of the liquids used in the experiments and range of Reynolds number investigated. The bounds of the contact angle $(\theta)$ interval correspond to the receding contact angle and to the advancing contact angle, respectively. The equilibrium contact angle $\left(\theta_{E}\right)$ lies in-between.

Figure 1. (a) Schematic representation of the experimental setup. (b) CAD (Computer Aided Design) model of the distributor. (c) Photograph of the setup. 1. Test plate 2. LED panel 3. High speed camera 4. Volumetric flow meters 5. Needle control valve 6. Spillway 7. Gear pump 8. Reservoir 9. CCI sensor 10. Distributor 11. Liquid Collector 12. Anti-vibration mount 13. Frame that holds the plate.

Figure 2. Perforated plate front view and cross-section along $x-z$ plane: (a) dimensions, coordinate system and definitions of perforation top edge, bottom edge and inner surface, (b) One face supply $\left(Q_{2} / Q_{1}=0\right)$, (c) two face supply with equal flow rates $\left(Q_{2} / Q_{1}=1\right)$. Arrows indicate the flow path followed by the fluid film before the curtain transition.

Figure 3. Film thickness profile in the $y=0$ plane far below the curtain transition: CCI measurements for perforation diameter $d=8 \mathrm{~mm}$, plate thickness $t=1 \mathrm{~mm}$, propan-2-ol, $\mathrm{Ka}=348, \operatorname{Re}=23$, supply conditions $Q_{2} / Q_{1}=0$ and $Q_{2} / Q_{1}=1$. The thick black segments on the $x$-axis correspond to the plate surface and the gap between them to the perforation. The origin of the coordinate frame coincides with the center of the perforation. The streamwise direction $(x)$ is rescaled by the capillary length $\left(l_{c}\right)$, and the current film thickness $(\delta)$ by the 
Nusselt flat film thickness $\left(\delta_{N u}\right)$ measured far upstream of the perforation. Insert: Image of the flow pattern far below the curtain transition, same experimental conditions, $Q_{2} / Q_{1}=1$.

Figure 4. Rim dynamics and transition to the curtain mode as a function of perforation diameter and $Q_{2} / Q_{1}$ : observations for plate thickness $t=1 \mathrm{~mm}$, propan-2-ol, $\mathrm{Ka}=348$. Re values are different since $\operatorname{Re}_{c r}$ depends on $d$. (a) Oscillating rim with circular hole $\left(d=4 \mathrm{~mm}, Q_{2} / Q_{1}=\right.$ $1, \mathrm{Re}=28)$; (b) Oscillating rim with bean-shaped hole $\left(d=8 \mathrm{~mm}, Q_{2} / Q_{1}=1, \mathrm{Re}=34\right)$; (c) Drops or liquid columns $\left(d=12 \mathrm{~mm}, Q_{2} / Q_{1}=0, \operatorname{Re}=29\right)$; (d) Pendant sheet $(d=12$ $\mathrm{mm}, Q_{2} / Q_{1}=1, \operatorname{Re}=32$ ).

Figure 5. Curtain images just beyond the transition: $t=1 \mathrm{~mm}, Q_{2} / Q_{1}=1$; (a) $d=4 \mathrm{~mm}$, propan-2-ol $(\mathrm{Ka}=348), \operatorname{Re}_{c r}=31$; (b) $d=8 \mathrm{~mm}$, propan-2-ol, $\operatorname{Re}_{c r}=37$; (c) $d=12 \mathrm{~mm}$, propan-2-ol, $\operatorname{Re}_{c r}=35 ;(\mathrm{d}) d=12 \mathrm{~mm}$, pure water $(\mathrm{Ka}=3920), \operatorname{Re}_{c r}=125$. The curtain exhibits parallel stationary waves in (b) and a rugged wave pattern in (c) and (d).

Figure 6. Free surface profile in the $y=0$ plane (stream wise direction) just beyond the curtain transition: CCI measurements (circles) for perforation diameter $d=8 \mathrm{~mm}$, plate thickness $t=1 \mathrm{~mm}$, propan-2-ol, $\mathrm{Ka}=348, \mathrm{Re}=36, Q_{2} / Q_{1}=1$. The thick black segments correspond to the plate surface. The origin of the coordinate frame coincides with the perforation center. The thin grey dotted lines are drawn to indicate the probable shape taken by the free surface of the film (data are missing because the local slope of the free surface is too steep for the CCI to capture the film thickness).

Figure 7. Variations of the curtain Reynolds number as a function of the perforation diameter rescaled by the capillary length $\left(d / l_{c}\right)$ for three plate thickness values $(t=0.5,1,1.5 \mathrm{~mm})$. 
The tested liquid is propan-2-ol $(\mathrm{Ka}=348)$. (a) One face supply. (b) Two face supply with equal volume flow rates.

Figure 8. Variations of the curtain Reynolds number as a function of $Q_{1} / Q_{2}$ for two different values of the perforation diameter $(d=4 \mathrm{~mm}$ and $d=8 \mathrm{~mm})$. The plate thickness is equal to $t=1 \mathrm{~mm}$. The tested liquid is propan-2-ol. $R e_{c r}$ is calculated from $Q_{1}^{c r}$, the volume flow rate on the front side that induces curtain transition at given $Q_{2}$.

Figure 9. Variations of the curtain Reynolds number as a function of the perforation diameter rescaled by the capillary length for four different liquids, i.e. propan-2-ol $(\mathrm{Ka}=348), 55 \mathrm{wt} \%$ glycerin aqueous solution $(\mathrm{Ka}=245), 25 \mathrm{wt} \%$ glycerin aqueous solution $(\mathrm{Ka}=1470)$ and pure water $(\mathrm{Ka}=3920)$. The plate thickness is equal to $t=1 \mathrm{~mm}$. (a) One face supply. (b) Two face supply with equal volume flow rates.

Figure 10. Section along the plane $y=0$ : idealized flat film profile on the perforated plate before the curtain transition. The red dotted lines represent the idealized curtain free surface.

Figure 11. Comparison between prediction of Eq. (4) (solid lines) and the experimental results (points) obtained with propan-2-ol $(\mathrm{Ka}=348)$ and perforated plates of thickness $t=1 \mathrm{~mm}$. (a) variations of $\mathrm{Re}_{c r}$ as a function of the perforation diameter rescaled by the capillary length for $Q_{2} / Q_{1}=0$ and $Q_{2} / Q_{1}=1$. (b) variation of $\operatorname{Re}_{c r}$ as a function of the ratio $Q_{1} / Q_{2}$ for perforation diameter $d=4 \mathrm{~mm}$.

Figure 12. (a) Measured half thickness profile of the curtain (squares) and calculated profile assuming free fall and omitting varicose waves (red solid line). (b) Predicted wavelength values 
along the liquid curtain (dashed line) and wavelength values measured on the waves that stand on the real curtain (crosses), same experimental conditions as Figure 6. 